\title{
NICOLÁS GÓMEZ DÁVILA, PENSADOR REACCIONARIO
}

\author{
Roberto Torretti \\ Universidad Diego Portales
}

\begin{abstract}
Resumen: El pensamiento e incluso el nombre de Nicolás Gómez Dávila (1913-1994) son prácticamente desconocidos en Chile. Este ensayo intenta corregir, en alguna medida, esta injusta e injustificable "conspiración del silencio". Propone una pequeña muestra, agrupada por temas, de sus aforismos o "escolios", acompañada de observaciones críticas. Después de un par de indicaciones sobre el método y el estilo del escritor bogotano y breves comentarios a tres "escolios" particularmente llamativos, se abordan reflexiones de Gómez Dávila sobre (i) la filosofía sensu stricto y la ciencia, (ii) Dios, el cristianismo y la religión, y (iii) el enfrentamiento de su pensamiento reaccionario con el pensamiento progresista moderno que anima igualmente a la democracia capitalista y socialista.
\end{abstract}

Palabras clave: aforística, filosofía y ciencia, religión, cristianismo, Dios, modernidad, civilización, igualitarismo, pensamiento progresista, pensamiento reaccionario.

Recibido y aceptado: diciembre 2012.

Roberto Torreti. D.H.C. Universidad Autónoma de Barcelona; Dr. Phil. Universidad de Freiburg i. Br.; Profesor emérito, Universidad de Puerto Rico. Miembro de número del Institut International de Philosophie y de la Académie Internationale de Philosophie des Sciences. Profesor emérito, Universidad Diego Portales (Santiago, Chile). Dirección electrónica: roberto.torretti@gmail.com. 


\section{NICOLÁS GÓMEZ DÁVILA, A REACTIONARY THINKER}

Abstract: The philosophy and even the name of Gómez Dávila (1913-1994) are almost completely unknown in Chile. In this essay I try to correct, to some extent, this unjust and unjustifiable silence regarding a forceful Spanish American thinker. I propose a small sample of his aphorisms or "scholia", grouped by subjects and supplemented with some critical remarks. After a few indications about the Colombian writer's method and style and short comments about three particularly striking "scholia", I deal successively with Gómez Dávila's reflections on (i) philosophy stricto sensu and science, (ii) God, Christianity and religion, and (iii) the confrontation between his reactionary thought and the modern brand of "progressive" thought that inspires both capitalist and socialist democracy.

Keywords: aphorism, philosophy and science, religion, Christianity, God, modernity, civilization, equalitarianism, progressive thought, reactionary thought.

Received and accepted: December 2012.

Vivir con lucidez una vida sencilla, callada, discreta, entre libros inteligentes, amando a unos pocos seres.

El que radicalmente discrepa no puede argüir, sino enunciar... Al reaccionario sólo le es dable proferir sentencias abruptas que se le indigesten al lector ${ }^{1}$.

$\mathrm{V}_{\mathrm{i}}$

por primera vez el nombre de Nicolás Gómez Dávila el 30 de noviembre de 2012, en una columna de Matías Rivas ${ }^{2}$. Esta censuraba duramente a los intelectuales chilenos que no leemos nada en la lengua en que aprendimos a hablar y solo comentamos y difundimos las obras de pensadores nacidos al norte de los Pirineos o del Río Grande.

1 Nicolás Gómez Dávila, Escolios a un texto implícito, 2009, pp. 263, 449. En adelante, remito a esta edición con la letra E seguida del número de la página; cuando necesito ser más preciso, asigno a los escolios de una página dada las letras minúsculas $a, b, c$, etc.; de este modo, "E, 290f" remite al sexto escolio de la p. 290.

2 Matías Rivas, "Arribismo académico", 30 de noviembre de 2012, p. 83 . 
Como ejemplo de lo que nos estamos perdiendo citaba justamente al escoliasta colombiano, "este filósofo más próximo, cuyo trabajo es contundente, mordaz y tan ineludible como el de" Emil Cioran. Si bien el término de comparación propuesto no era particularmente impresionante para mí (que nunca me embelesé con el autor rumano, y no he pasado años leyéndolo, sino a lo sumo unas horas), la lectura de los aforismos o "escolios" de Gómez Dávila citados por Rivas me impulsó a buscar qué más había suyo en internet. Hallé, bajé y leí rápidamente su último libro ${ }^{3}$, y encargué a Amazon.es la edición completa de sus escolios citada en la nota 1. Consignaré aquí mis reflexiones al respecto, en un intento improvisado y tardío de esquivar los reproches de mi apreciado editor y amigo. Omito repetir los datos biográficos que el lector interesado puede hallar, igual que yo, en el sitio web http://de.wikipedia.org/ wiki/Nicolás_Gómez_Dávila y otros allí mencionados.

Gómez Dávila llama 'escolios' a lo que yo llamaría 'aforismos' (y una persona joven disfrutaría como 'twits') ${ }^{4}$, porque los concibe, al parecer, como glosas a un texto o colección de textos preexistente que él lee y comenta. No nos dice en qué consiste este "texto implícito", pero por el contenido de los escolios que le dedica cabe identificarlo con el devenir del mundo en que vive el autor, o con su propio stream of thought, o con lo que logró leer de su biblioteca personal de 30.000 volúmenes ${ }^{5}$. En uno de sus escolios, rechaza expresamente el nombre

${ }^{3}$ Nicolás Gómez Dávila, Sucesivos escolios a un texto implícito, 1992.

${ }^{4}$ Mi joven amigo Joaquín Trujillo Silva me informa que Gómez Dávila tiene una cuenta Twitter, póstuma, con 7.701 seguidores: https://twitter.com/escolios. De hecho, son pocos los escolios suyos que ocupan más de 140 caracteres.

5 En su "Semblanza de un Colombiano Universal: las claves de Nicolás Gómez Dávila”, 1988 (pp. 9-20), Francisco Pizano de Brigard ofrece una interpretación más precisa y convencional: el "texto implícito" sería el "centón reaccionario" que Gómez Dávila incluyó en Textos I (1959, pp. 61-100), reproducido en Textos (2010, pp. 55-84), donde expone, "sin ningún propósito didáctico", las líneas esenciales de su visión del hombre. Esta interpretación, publicada en vida de Gómez Dávila por alguien que lo conoció personalmente, es más verosímil que las fantasías que propuse arriba, y también hay un escolio que apunta en ese sentido ("Todo escritor comenta indefinidamente su breve texto original"-E, 171). Sin embargo, después de leer el presunto "texto implícito", estimo que su ideario escuálido les queda muy corto a los escolios, cuya prosa eximia, además, no se condice con el estilo patéticamente rimbombante de aquel. Por otra parte, si los escolios se referían precisamente a ese texto, ¿qué le habría costado al autor indicar la página y las líneas comentadas en cada uno, como hicieron los escoliastas griegos? 
de 'aforismo', que etimológicamente connota delimitación y separación: "El lector no encontrará aforismos en estas páginas. Mis breves frases son los toques cromáticos de una composición pointilliste" (E, 69). Al asimilar así su obra al arte de Seurat y Signac, y no a otro, Gómez Dávila le está adjudicando no solo unidad y coherencia — que sin duda las tiene- sino además un orden calculado que no es fácil discernir en ella. Más que la geometría deliberada y manifiesta de "La tarde de verano en la Grande Jatte", el conjunto de los escolios de Gómez Dávila evoca la elusiva unidad que recorre una gran composición musical. Como él mismo dice: "Un conjunto personal de soluciones auténticas no tiene coherencia de sistema sino de sinfonía" (E, 867).

El primer escolio de todos parecería destinado a indicar el alcance que su autor asigna a los demás: "Un texto breve no es un pronunciamiento presuntuoso, sino un gesto que se disipa apenas esbozado" (E, 69). Si los entendía así, no es sorprendente que haya hecho imprimir más de uno que no pasa de ser un bon mot ingenioso ("Socialismo es el nombre comercial del capitalismo de estado en el mercado electoral"E, 867; "El que denuncia las limitaciones intelectuales del político olvida que les debe sus éxitos"-E, 252; "El único antídoto a la envidia, en las almas vulgares, es la vanidad de creer que nada tienen que envidiar"-E, 297), o a lo sumo una máxima moral que recuerda a La Rochefoucauld en cuanto a la forma ("Todo el mundo se siente superior a lo que hace, porque se cree superior a lo que es. Nadie cree ser lo poco que es en realidad"-E, 347; "El rico, en la sociedad capitalista, no sabe usar del dinero para lo que mejor sirve: para no tener que pensar en él"-E, 1172) o incluso literalmente ("La hipocresía no es la menos eficaz propedéutica de la virtud"-E, 472). Unos pocos contienen una exageración tosca ("El hombre no quiere sino al que lo adula, pero no respeta sino al que lo insulta"-E, 101) o sutil ("Cuando todos quieren ser algo sólo es decente no ser nada"-E, 393), o un eslogan emotivo pero opaco ("La obra de arte es un pacto con Dios"-E, 294; "Quien no vuelva la espalda al mundo actual se deshonra"-E, 93). Y algunos se quedan en mera confidencia íntima ("Mis convicciones son las mismas que las de la anciana que reza en el rincón de una iglesia"-E, 1320; "Más que cristiano, quizás soy un pagano que cree en Cristo"E, 314; "Mis santos patrones: Montaigne y Burckhardt"-E, 409), aunque Gómez Dávila nos prevenga que "por tonto que sea un catecismo, siempre lo es menos que una confesión personal de fe" (E, 259). 
Pero en general sus escolios cumplen la norma prescrita por él: "La aserción breve no debe ser ocurrencia repentina, sino conclusión lacónica" (E, 1304). Para quien, como yo, no se propone creer, sino ir entendiendo, y con Unamuno asume que no "quedará" en nada, aunque pase por todo ${ }^{6}$, el despliegue de ocho mil y tantas conclusiones, por muy escueta y punzante que sea cada una, aparece, a primera vista, como una fatigosa exhibición de exuberancia. Preferiría nadar como pez en la red de arroyuelos discursivos que desembocan en esas conclusiones, antes que reposar en seco, varado en ellas. Con todo, las conclusiones de Gómez Dávila, "de pocas líneas pero llenas de fuerza", suelen dar en un blanco más o menos significativo dentro del repertorio de intereses de un sudamericano educado de mi tiempo, aunque, como es propio de este género literario, olviden o pasen a llevar una multitud de implicaciones y consideraciones pertinentes. $\mathrm{Y}$ las hay que calan a fondo, con una sutileza y penetración sin paralelo en la literatura sudamericana que conozco.

Antes de abordar algunos de los aciertos sesgados sobre toda clase de asuntos que, más o menos aleatoriamente, han solicitado mi atención en la obra de Gómez Dávila, destacaré tres piezas de caza mayor, que nos ayudarán a calibrar el temple del personaje con quien tenemos que habérnoslas.

Más que del inquietante espectáculo de la injusticia triunfante, es del contraste entre la fragilidad terrestre de lo bello y su esencia inmortal en donde nace la esperanza de otra vida (E, 1326).

Se requiere hoy tan exclusiva aplicación a un solo tema para saber algo a fondo que la inteligencia se mutila aprendiéndolo (E, 1299).

${ }^{6}$ Aludo a la respuesta de don Miguel a un majadero que, durante una discusión, le preguntó “¿En qué quedamos?”: “Usted, no lo sé; pero yo no quedo en nada, porque paso por todo" (Unamuno, Visiones y comentarios, 1949; p. 123). Por su parte, Gómez Dávila ha escrito que "no existe verdad en que sea lícito descansar" (E, 289). Y que "el más sutil disfraz de la estupidez es la brevedad epigramática" (E, 241).

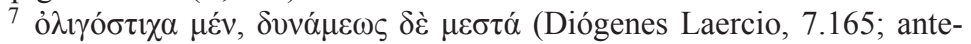
puesto como epígrafe a Escolios 1 (E 67). 
Si queremos que la "civilización" sea otra cosa que un repertorio de técnicas en manos bárbaras, el ascenso social debe ser raro y lento (E, 1368).

La fragilidad terrestre de lo bello inspiró al poeta jesuita Gerard Manley Hopkins versos sobrecogedores en donde se pregunta si no hay un medio, un lazo o clave que impida que se esfume la belleza. Y entrega la respuesta: "No hay ninguno, no no no, ninguno; así que empieza a desesperar" ${ }^{\text {"8 }}$. El primer escolio citado puede leerse como glosa al poema de Hopkins: Tienes que desesperar, sí; a menos que tu fe en Jesucristo te faculte para esperar el día en que los cuerpos se levantarán incorruptibles. Por otra parte, para el lector hispanoamericano de hoy, aturdido por sesenta años de prédica paleomarxista o neocatólica, lo más llamativo de este escolio será la prioridad que asigna a la belleza sobre la justicia, como aquello cuyo maltrato en esta vida nos mueve a desear otra tan intensamente que lleguemos incluso a esperarla. Pero tal inversión de la consabida jerarquía de valores no es sorprendente en Gómez Dávila, quien también ha escrito: "Sólo una cosa no es vana: la perfección sensual del instante" (E, 98)9.

El escolio siguiente pone el dedo en la llaga del intelectual de hoy, constreñido a optar entre el amateurismo que disipa y la especialización que ciertamente mutila. El dilema solo podría resolverse - por un tiempo - con una mutación que decuplique el cerebro y sus sinapsis; pero es sumamente inverosímil que ello ocurra, sobre todo si la política pública favorece más bien la supervivencia y fijación de genes que lo achican. Se comprende que un gentleman scholar decimonónico, que puede lo mismo ser poeta y presidente, redactar códigos o traducir a Platón, repudie una cultura que lo ponga en la situación descrita. Pero quien entienda y acepte que la historia continuará viviéndose hoy, y mañana, y hasta después de sus días, no tiene esa alternativa. La especialización disciplinaria no admite vuelta atrás, a menos que se deseche lo que se ha

8 "How to keep — is there any any, is there none such, nowhere known some, bow or brooch or braid or brace, lace, latch or catch or key to keep / Back beauty, keep it, beauty, beauty, . . . from vanishing away? / ..... / O there's none; no no no there's none: / So be beginning to despair, to despair, / Despair, despair, despair, despair" (Gerard Manley Hopkins, sj, "The leaden echo and the golden echo", http://www.bartleby,com/122/36html).

9 También dice, no sé si contra o con el poeta del Fausto: "La momentánea belleza del instante es lo único que concuerda en el universo con el afán de nuestras almas" (E, 88). 
llegado a saber, lo cual, diría yo, es aún más improbable — sin un retorno global a la edad de piedra - que la renuncia a las comodidades modernas reclamada por los ecómanos. La vida inteligente de la humanidad consistirá en la convivencia de intelecciones inacabadas y fragmentarias; en lo cual, por lo demás, ha consistido siempre, solo que en adelante tendrá que hacerlo a sabiendas, sin las pretensiones de verdad absoluta y alcance total que la han manchado hasta ahora.

La tercera pieza mayor destacada arriba es una bofetada en la cara de todos los partidos políticos que hoy por hoy concurren a elecciones en Latinoamérica (e incluso en todo el mundo). Izquierda y derecha promueven igualmente la llamada movilidad social, aunque aquella prefiera la vía de la redistribución de los ingresos, y esta la carrera abierta a los talentos. En otros escolios, Gómez Dávila reprueba ambos caminos, en cuanto son fuente o manifestación de envidias ${ }^{10}$. Pero en el que aquí comento se atreve a vindicar con una observación mucho más incisiva su políticamente incorrectísima postura. Es un texto tan escandaloso que Rosa Emilia Gómez de Restrepo lo omitió en su florilegio de escolios de su padre ${ }^{11}$, aunque ninguno de los que incluye aduce como este razones de bien común en apoyo de su extremismo reaccionario. Quienes detestamos visceralmente toda forma de jerarquía hereditaria no nos dejaremos inmutar por la lúcida advertencia de Gómez Dávila; querremos abolirlas aunque sea al precio de una desfiguración completa de lo que hasta ahora hemos llamado 'civilización'. Pero está bien que nos prevenga sobre el riesgo que se corre al promover a puestos de mando a personas que solo tienen educación superior (und keine Kinderstube, como dicen los alemanes). Por otra parte, cualquiera que haya manejado un smartphone para conversar, y fotografiar, y leer a Gómez Dávila en el metro sabe que estas técnicas ofrecen una escuela de delicadeza a sus dedos bárbaros.

10 "En las sociedades donde el cargo social, en lugar de adherir a la persona, constituye meramente un transitorio encargo, la envidia se desboca. $L a$ carrière ouverte aux talents es el hipódromo de la envidia" (E, 653). "El que es partidario de la igualdad sin ser envidioso, sólo puede serlo porque es bobo" (E, 594). 2001 .

${ }^{11}$ Nicolás Gómez Dávila, Escolios a un texto implicito. Selección, 
La sucesión incansable de los escolios salta de un tema a otro, siguiendo hilos que se entrecortan y entrelazan. En el espacio de que dispongo puedo dar solo una muestra muy pequeña, que abra el apetito de seguir leyendo, aunque sea solo aquí y allá, en el libro entero. Empiezo con lo que me resulta más cercano: las reflexiones que Gómez Dávila dedica a la filosofía sensu stricto y a la ciencia. Sigo con los asuntos que más le importan a él: Dios, el cristianismo, la religión. Termino con aquellos que ofrecen mayor interés a la mayoría de los lectores: el enfrentamiento del pensamiento reaccionario de Gómez Dávila con el pensamiento progresista moderno que anima igualmente a la democracia capitalista y socialista.

De las tres formas — arte, religión, filosofía - que según Hegel adopta el "espíritu absoluto", Gómez Dávila demuestra comprensión y cariño a la primera, profesa devoción incondicional a la segunda, pero ante la tercera exhibe la admiración recelosa de un outsider ${ }^{12}$, no exento de acritud ${ }^{13}$. Bajo la perspectiva hegeliana acorde con mi propio compromiso vocacional, estos son signos de subdesarrollo ${ }^{14}$. Pero no abun-

12 Solo un "afuerino" puede sostener que "la precisión en filosofía es una falsa elegancia", mientras que "la precisión literaria es fundamento del acierto estético" (E, 961). Su admiración, implícita en las numerosas referencias a Platón, Kant y Hegel, se hace explícita cuando declara que "toda filosofía es de una insolencia admirable" (E, 253), luego de haber dicho que "nada [lo] seduce tanto en el cristianismo, como la maravillosa insolencia de sus doctrinas" (E, 128).

13 "Los que se ocupan de filosofía no la tomarían tan en serio, si generalmente no vivieran de profesarla"-E, 1360. "El gremio de filósofos profesionales sufre de inanición filosófica si no ingurgita, de vez en cuando, un aficionado: Sócrates, Descartes, Hume, Kierkegaard, Nietzsche" (E, 481). Por otra parte, Gómez Dávila tiene muy claro que "el pensamiento que se cree capaz de eludir las pautas del gremio, repite siempre meramente filosofemas elementales", pues "la filosofía es tradición, profesión, oficio; institución, en fin" (E, 229), y "sin ser cumulativa, sólo avanza asumiendo en cada etapa la totalidad de su pasado" (E, 564).

14 Subdesarrollo sugiere también la categorización de personas e ideas como "inteligentes" o "tontas", hábito inveterado de clase alta en Chile y parecería que también en Colombia. Dice característicamente: "Prefiero la parcialidad cortante y esbelta de un hombre inteligente a la imparcialidad babosa de un tonto" (E, 806). A veces recurre a estas categorías familiares para comunicar observaciones lapidarias, tales como: "La estupidez es el crimen imperdonable de una clase ociosa, ya que ser inteligente es la justificación de su existencia" (E, 318) y "El tonto no debe su tontería a la mediocridad de su inteligencia, sino a la vulgaridad de su alma" (E, 747). Pero su uso desmedido delata en el propio 
daré en ello, pues mi propósito aquí no es situar a Gómez Dávila en la historia y geografía del espíritu, sino alentar a leerlo. Con ese propósito, cito sin comentarios siete pronunciamientos filosóficos suyos que estoy dispuesto a sostener sin mayor reserva:

Sólo hay instantes (E, 404).

La historia es la serie de universos presentes a la conciencia de sujetos sucesivos (E, 464).

Toda verdad es riesgo que asumimos apoyándonos sobre una serie indefinida de evidencias infinitamente pequeñas (E, 290).

La verdad se pervierte cuando olvida el concreto proceso en que nace $(\mathrm{E}, 72)$.

Nada de lo que acontece es necesario, pero todo se vuelve necesario una vez acontecido (E, 306).

En el universo hay islotes de orden. Pero el supuesto orden del universo es artefacto ideológico (E, 651).

El filósofo no demuestra, muestra. Nada dice al que no ve (E, 889).

De los dos siguientes diría que son lúcidos y atinados, siempre que acotemos su alcance.

Verdad es la fórmula que expresa fielmente nuestra visión de un objeto. Siendo relación entre el objeto que se evidencia y la persona para quien es evidente, la verdad está ligada a una intuición concreta. La fórmula deja de ser verdad para quien no puede reconstruir con ella la experiencia que la funda (E, 315).

Sin actos intencionales los hechos no son ni necesarios, ni casuales. Sin intenciones, el mundo es bloque de sucesiones brutas. La intención funda la casualidad cuando las cosas la sorprenden y la causalidad cuando no la desconciertan (E, 74).

usuario una inteligencia exenta de matices. En Escolios para un texto implícito, la palabra 'tonto/a' aparece 212 veces en singular o plural; 'tontería(s)', 39; 'bobo/a' y 'bobería(s)', 75; 'imbécil(es)' e imbecilidad(es)'; estúpido/a' y 'estupidez(ces)', un total de 141. Por otra parte, 'inteligente(s)' aparece 234 veces. En suma, las voces que expresan la referida categorización figuran 810 veces en el libro, lo que viene a ser una vez cada diez escolios. No contabilizo las 351 veces que figura la palabra 'inteligencia', porque Gómez Dávila la emplea más bien como nombre de una facultad activa del espíritu humano, y no de esa aptitud individual que — disociada de todo cultivo - es común atribuir a algunas personas y denegar a otras en el cotorreo de los grupos aludidos. 
El primer escolio logra zafarse, creo, de la concepción vulgar de la verdad como adecuación de lo que se dice a lo que hay, pero adhiere aparentemente a la noción de que la verdad se deja encerrar en una "fórmula", consistente en uno o más enunciados verbales, sin considerar la trama de conceptos y proyectos en que esos enunciados se encuadran y adquieren su sentido. (A menos, claro, que entendamos que cuando Gómez Dávila habla de "reconstruir" la experiencia que "funda" la verdad alude entre otras cosas a esa trama o tinglado sin el cual dicha experiencia no habría llegado a construirse). El segundo escolio subordina a la existencia de propósitos, y por ende de proyectos, la atribución de causalidad o casualidad al acontecer; se trataría pues de una afirmación particularmente concisa y perentoria del pragmatismo prevaleciente en la filosofía de hoy y que, a la zaga de Heidegger y Wittgenstein, ciertamente suscribo. Pero el escolio solo se deja entender de esta manera si el autor habla de intenciones humanas y, cuando subraya el lado brutal de un mundo sin intenciones, no busca resucitar el argumento del designio. La mención al final de unas cosas que "sorprenden" a la intención y otras que "no la desconciertan" confirma, diría yo, esta interpretación.

Particularmente atractivo para el lector de hoy es el firme repudio de la unidad y homogeneidad de todo, que cierta tradición filosófica propugna: "Llámase monismo la vana tentativa de ensamblar los rotos fragmentos del universo" (E, 172). "El monismo es actitud que viola la mitad de la experiencia" $(\mathrm{E}, 1394)^{15}$. Contra esa tradición obsoleta, y en buena sintonía con lo mejor del pensamiento actual, Gómez Dávila profesa resueltamente el pluralismo:

La pluralidad empírica de sistemas simbólicos es indicio de una pluralidad de referendos recíprocamente irreductibles. Solamente podemos referirnos a la totalidad de los referendos empleando la totalidad de los sistemas $(\mathrm{E}, 368)^{16}$.

15 Hay otras menciones inamistosas del monismo en E, 405c, 472e, $1004 d$.

${ }^{16}$ La segunda oración insinúa o supone — no sé con qué base- que hay tales totalidades. Cuesta deshacerse de la vocación totalitaria de la razón humana. Ella asoma también, diría yo, en el sugestivo escolio siguiente (que nos recuerda la idea de convergencia a la verdad, propuesta por Peirce) : "Toda proposición ajustada a su evidencia conserva su validez, aun cuando otra de más honda procedencia posteriormente la englobe. La historia del pensamiento no es evolución, ni proceso dialéctico, sino aparición contingente de los fragmentos de una estructura donde cada verdad halla su sitio" (E, 201). 
Cierro esta sección con un escolio que pudo haber sido inspirado por la lectura de Borges ${ }^{17}$ : "Las metafísicas suelen ser fábulas amenas que el filósofo expande en novelas tediosas" (E, 863).

Gómez Dávila opina también sobre la ciencia natural, reconocido baluarte de la modernidad que aborrece, aunque aquella al parecer le es bastante más ajena que la filosofía ${ }^{18}$. Reiteradamente subraya sus límites (E, 1004b, 1272a, 1342h, 1366h, 1380d), sin advertir que, en rigor, se trata de los límites de cada propuesta científica, y que "la ciencia", en cuanto actividad humana duradera y cambiante, puede traspasarlos y los traspasa todo el tiempo. Toma de Popper la concepción de la ciencia como acervo de proposiciones hipotéticas falsables (E, 84c, 355d) y del progreso científico como "la misma empresa" de su falsación (E, 383c), sin atender ni un instante a la creación de los conceptos requeridos para el enunciado de tales proposiciones, y al diseño de los experimentos en que se las pone a prueba. El largo escolio siguiente, aunque recurre a términos poco habituales entre los epistemólogos, enuncia sin embargo, somera y más certeramente que la gran mayoría de ellos, rasgos cardinales del saber científico que ojalá fueran mejor conocidos y reconocidos.

La ciencia no es escala de Jacob para ascender hasta un empíreo cristalino de incorruptibles verdades. Como sus proposiciones no provienen de un proceso de experimentación que las imponga, la suma momentánea de proposiciones falsificables en que consiste no libera al hombre de su servidumbre a la historia. No existiendo proposiciones verificadas que emerjan de las aguas del tiempo, tanto la conciencia constructora como el objeto construido fluyen sumergidos en la historia. Salvo las tautologías, sólo existen estados históricos de una ciencia $(\mathrm{E}, 370)$.

${ }^{17}$ Véase Cordua, "Borges y la metafísica", 1988, pp. 629-638.

18 Visiblemente tiene mucho más afinidad con las llamadas ciencias humanas y sobre todo con la historiografía. Al respecto ha escrito escolios notables, tales como E, 175b, 305b, 346h, 368b, 369a, 411d, 476b, 484b, $541 e, 632 g, 675 d, 676 c, 731 e, 732 g, 734 b, 815 f, 826 f, 844 d, 883 b, 901 f, 904 a$, $921 c, 922 f, 934 e, 941 d, 964 c, 968 d, 1024 c, 1108 a, 1201 c, 1206,1278 f, 1290 e$, $1320 h, 1322 b, 1341 c, 1343 c, 1344 f, 1364 h, 1392 c, 1398 a$. 
Por último, quiero mencionar el impacto que me causó la exclamación siguiente, sin precedentes entre los filósofos e historiadores de la ciencia que he estudiado y, quizás por lo mismo, tan refrescante:

¡Maravillosa insolencia de toda constatación empírica! (E, 162).

Leyéndola imaginé a Oersted, atónito de ver cómo la aguja imantada giraba hasta apuntar en una dirección transversal al alambre conductor de electricidad con el que la había alineado; a Becquerel perplejo ante las placas fotográficas manchadas por la presencia de sales fosforescentes (¡dentro de un cajón cerrado y sin luz!); a Rutherford estupefacto cuando su ayudante Marsden le comunica los resultados del bombardeo con partículas alfa de una finísima lámina de oro. ("It was almost as incredible as if you fired a 15-inch shell at a piece of tissue paper and it came back and hit you").

Si Gómez Dávila se presenta como receloso y distante de la filosofía y las ciencias que son mi fuente de luz, no puede sorprender que yo me sienta completamente extraño a la religión que nutre su vida. Me confieso enteramente incompetente para elucidar su pensamiento al respecto $\mathrm{y}$, en ciertas ocasiones, incluso para entender sus palabras. Pero, si me he puesto a escribir sobre él para descorrer un poquito el velo de ignorancia que hasta ahora lo ha mantenido oculto en Chile, no puedo dejar de decir algo sobre la pieza de mayor calado en su personalidad de pensador.

Cito, de entrada, un escolio que deslinda nítidamente su religión y mi filosofía: "O Dios, o el azar: todo término distinto disfraza lo uno o lo otro" (E, 296). Inmediatamente me siento tentado a completarlo con otro que lo aclara y las reúne: "Casualidad es un nombre que damos a Dios, tanto por respeto humano como por respeto divino" (E, 438). Como, según esto, 'casualidad' sería otro nombre de lo mismo que llamamos con el nombre de 'Dios', este escolio se deja leer al revés — "Dios es un nombre que damos a la casualidad"-, aunque, claro, en esta lectura, el segmento explicativo tendría que reemplazarse con otro. (Y para un amante de las letras clásicas lo indicado sería decir 'Diosa', no 'Dios': Túxๆ y Fortuna son nombres de mujer). Sin embargo, examinando las 304 ocasiones en que la palabra 'Dios' —en singular y con mayúscula- 
aparece en los Escolios, se comprobará que en casi todas ellas es imposible reemplazarla salva veritate con 'la casualidad'. Baste un ejemplo:

El clero moderno cree poder acercar mejor el hombre a Cristo, insistiendo sobre la humanidad de Jesús. Olvidando así que no confiamos en Cristo porque es hombre, sino porque es Dios (E, 1385).

Es claro entonces que, para Gómez Dávila, no en cualquier contexto 'la casualidad' designa lo mismo que 'Dios'. Aunque esta palabra aparece en su libro en muchos contextos diferentes, no logro saber precisamente qué —o quién- es lo que intenta denotar con ella. Él mismo reconoce que "no es tanto que la mentalidad moderna niegue la existencia de Dios como que no logra dar sentido al vocablo" (E, 398). Pero quizás el lector corra mejor suerte que yo con los pasajes que copiaré a continuación. Hallo en los Escolios dieciséis enunciados de la forma Dios es..., donde la cópula va seguida por un sintagma nominal; cito nueve:

Dios es el creador, no la primera causa (E, 744).

Dios es el término con que le notificamos al universo que no es todo (E, 483).

Dios es la condición trascendental de la absurdidad del universo (E, 105).

Dios es la condición trascendental de nuestro asco (E, 217).

Dios es la razón del sabor en la cosa que deja de ser insípida (E, 479)

Dios es esa sensación inanalizable de seguridad a nuestra espalda (E, 834).

Dios es el nombre del único enigma cuyo descifre no sería un desengaño (E, 378)

Dios es lo que elude toda prueba (E, 354).

Dios es la substancia de lo que amamos (E, 105).

Para el último hay una glosa que quizás lo aclare: "La belleza del objeto es su verdadera sustancia" $(E, 177)^{19}$. Menos sucinto que los

${ }^{19}$ En ambas citas transcribo literalmente el original. Quizás Gómez Dávila veía una diferencia esencial entre 'substancia' y 'sustancia'; usa la segunda grafía solo en E, 177a, arriba citado, y en E, 1366g: "Los acontecimientos históricos graves alteran la sustancia misma de los pueblos"; la primera, en cambio, en 16 ocasiones, por ejemplo, en E, 96e: "Si bien y mal, fealdad y belleza, no son substancia de las cosas, la ciencia se reduce a una proposición breve: lo que es es". 
anteriores es el décimo enunciado con la susodicha forma ${ }^{20}$, que cito en su contexto:

Dios no es substituto de placeres ausentes, de apetitos sofrenados, de codicias incumplidas. Dios es la presencia invisible que corona la plenitud terrestre más colmada, el éxtasis más alto de la dicha más ebria, la hermosura en que florece la hermosura. Dios no es compensación inane de la realidad perdida, sino el horizonte que circunda las cumbres de la realidad conquistada. (E, 191).

Mayor luz sobre el referente de 'Dios' que esta batería de enunciados categóricos que atribuyen a un mismo sujeto una abigarrada variedad de predicados, arrojan quizás ciertos pronunciamientos de Gómez Dávila sobre la manera cómo ese referente "nace" 21 , dónde se muestra, cómo es posible y no es posible conocerlo.

Dios nace donde un mito etiológico se combine con una experiencia sagrada $(\mathrm{E}, 124)$.

Tan grande es la distancia entre Dios y la inteligencia humana que sólo una teología infantil no es pueril $(\mathrm{E}, 523)^{22}$.

${ }^{20}$ Los otros seis figuran en E, 327e, $514 g, 529 d, 533 a, 803 f, 1151 d \mathrm{y}$ $1296 f$.

${ }^{21}$ Sobre el "nacimiento" de Dios, Gómez Dávila escribió en Textos I (la colección de ensayos sin nombre publicada en 1959 que cité en la nota 5) un párrafo que me acerca más a la religión del autor que los magros escolios citados: "El aparato mental del hombre no difiere del aparato mental del homínida. El hombre es un animal que la percepción, misteriosamente concedida, de un nuevo objeto coloca en un universo bruscamente invadido por una presencia que lo agrieta. En el silencio de los bosques, en el murmullo de una fuente, en la erguida soledad de un árbol, en la extravagancia de un peñasco, el hombre descubre la presencia de una interrogación que lo confunde. Dios nace en el misterio de las cosas. Esa percepción de lo sagrado, que despierta terror, veneración, amor, es el acto que crea al hombre, es el acto en que la razón germina, el acto en que el alma se afirma. El hombre aparece cuando Dios nace, en el momento en que nace, y porque Dios ha nacido" (Textos, 2010, p. 48; cursiva mía). Anoto solamente que, según los testimonios -indirectos y muy posteriores- que tenemos de ese evento, lo que nació "en el misterio de las cosas" para el hombre y quizás también con el hombre, fueron dioses y diosas: Tláloc, Atenea, Ganesh, Ceres, Yahveh...

${ }^{22}$ Cierta relación con este guardan los escolios siguientes: "La utilidad pedagógica de las prácticas supersticiosas se debe a la ausencia de nexo inteligible entre los medios que emplean y los fines que buscan. Solo la superstición 
Toda obra de arte nos habla de Dios. Diga lo que diga (E, 582).

Dios no sería Dios, si nuestro modo de conocerlo figurara en manuales de psicología (E, 622).

Dios no es objeto de mi razón, ni de mi sensibilidad, sino de mi ser. Dios existe para mí en el mismo acto en que existo. (E, 288)

Para dudar de la existencia de Dios bastaría que existieran pruebas de que existe. Un Dios implicado por el universo no sería el Dios en que creemos (E, 530).

La existencia de Dios es indemostrable, porque con una persona tan sólo podemos tropezar (E, 920).

La existencia de Dios es proposición analítica para el que se siente creatura (E, 923).

Sentirse creatura es sentirse contingente, pero misteriosamente albergado (E, 1008) ${ }^{23}$.

Los dos últimos textos hablan de sentirse creatura, una expresión que figura también en E, 1005b; en 194b y 497e hallamos la variante vivirse como creatura; conciencia de creatura en $909 e$; y en $234 e$ y $945 a$ se habla de nuestra condición de creatura, la misma que, nombrada en alemán, ocupa un lugar decisivo en el que, a mi modo de ver, es el texto clave del pensamiento político de Gómez Dávila:

El pensamiento progresista deriva de la creencia en nuestra Mündigkeit. El pensamiento reaccionario de la conciencia de nuestra Kreatürlichkeit (E, 660).

Mündigkeit, que significa 'mayoría de edad', alude, me parece, muy claramente a la respuesta que dio Kant a la pregunta ¿Qué es la ilustración? "Ilustración es el egreso del ser humano de la minoría

le enseña a la muchedumbre que no hay técnica racional de lo importante" (E, 461). "Si las supersticiones desaparecieran, la teología liquidaría rápidamente a la religión" (E, 459). "El catolicismo languidece cuando rehúsa nutrirse de substancia pagana" (E, 311). "Más que cristiano, quizás soy un pagano que cree en Cristo" (E, 314). "El cristianismo completa el paganismo agregando al temor a lo divino la confianza en Dios" (E, 1248).

${ }^{23}$ Cf. E, 834c, citado arriba; E, 267e: "Tanto mi religión como mi filosofía se reducen a confiar en Dios"; E, 1147i: "Un Dios inteligible no sería un Dios confiable". 
de edad en que se halla por su culpa" (Aufklärung ist der Ausgang des Menschen aus seiner selbst verschuldeten Unmündigkeit) ${ }^{24}$. Kreatürlichkeit significa precisamente 'condición de creatura'. Cuando me topé por primera vez con este notable pasaje, anoté al margen: "Kreatürlichkeit es un atributo inferido; lo inmediatamente percibido es nuestra Bedürftigkeit [condición menesterosa], que claramente no podemos suprimir, pero que nuestra Mündigkeit demanda que busquemos aunque solo sea parcialmente remediar". Pero a poco andar, leyendo textos como los citados arriba, comprendí que Gómez Dávila no solo se sentía menesteroso, como cualquier hijo de vecino, sino inmediatamente creatura de Dios. De hecho, trata como expresiones equivalentes "la conciencia de nuestra dependencia, de nuestra impotencia, de nuestra insignificancia" y "la conciencia de nuestra condición de creatura" 25 . Y esta última, como hemos visto, entraña por sí misma la existencia de Dios (E, 923b, citado arriba).

En esa misma conciencia basa entonces Gómez Dávila - conforme al texto clave arriba transcrito (E, 660a) - su rechazo de la democracia, del igualitarismo, del capitalismo y el socialismo, del consumismo y la solidaridad. Aunque reconoce que el pensamiento reaccionario es impotente (y lúcido-E, 384) y que el reaccionario mismo es hoy "meramente un pasajero que naufraga con dignidad" (E, 427), ha escrito cientos de aforismos donde escarnece a la modernidad y sus propaladores de todo perfil y pelaje, particularmente esa bête noire que es para él "el clérigo progresista" (E, 379a, 446a, 449a, 654a, 704g) ${ }^{26}$. Lo justifica diciendo que "el reaccionario no escribe para convencer", sino que "meramente transmite a sus futuros cómplices el legajo de un pleito

${ }^{24}$ Kant, Gesammelte Schriften, Berlin: 1902- , t. VIII, p. 35.

25 E, 234e: "La conciencia de nuestra dependencia, de nuestra impotencia, de nuestra insignificancia, la conciencia, en fin, de nuestra condición de creatura, nos salva de la angustia y del tedio".

${ }^{26}$ Además de los cinco escolios citados, hay otros treinta y tantos donde habla despectivamente del "clero progresista", "clero moderno", "clero actual" o "nuevo clero". Cito dos: "Solamente porque ordenó amar a los hombres, el clero moderno se resigna a creer en la divinidad de Jesús; cuando, en verdad, es sólo porque creemos en la divinidad de Cristo que nos resignamos a amarlos" (E, 362). "En su afán pueril y vano de seducir al pueblo, el clero moderno concede a los programas socialistas la función de esquemas realizadores de las Bienaventuranzas. [...] El clero moderno predica, en otros términos, que hay una reforma social capaz de borrar las consecuencias del pecado. De lo que se puede deducir la inutilidad de la redención por Cristo" (E, 1403). 
sagrado" (E, 861). Pero piensa también que "el mundo moderno no es una calamidad definitiva. Existen depósitos clandestinos de armas" (E, 312). Si bien limita su ambición "a practicar contra el mundo moderno un metódico sabotaje espiritual (E, 431), exhorta a "disparar con cualquier arma, desde cualquier matorral, sobre cualquier idea moderna que se avance sola en el camino" (E, 433).

Según Gómez Dávila, el progresismo moderno proviene de herejías condenadas por los grandes concilios del episcopado católico en la antigüedad tardía, especialmente de las comprendidas bajo el nombre 'gnosticismo'27. Expulsadas del primer plano de la cristiandad, perviven ocultas "en villorrios montañeses, en conventículos de ciudades fronterizas, y entre las legiones del imperio. [...] La moderna religión democrática se plasma, cuando el dualismo bogomilo y cátaro se combina, y fusiona, con el mesianismo apocalíptico. [...] Solamente cuando el rector de la horda gemebunda, el constructor de la Jerusalén celeste, el juez del tribunal irrecusable, es el hombre mismo, el hombre solo; cuando el dios caído de las heterodoxias gnósticas se confunde con la hipóstasis soteriológica de la teología trinitaria; solamente cuando el Mesías prometido es la humanidad divinizada; solamente entonces el hombre-dios de la religión democrática se yergue, lentamente, de su lodo humano" (Textos. Madrid, Atalanta, 2010; pp. 73-75). "Gnosticismo y cristianismo parten del mismo punto en direcciones divergentes. De una misma definición de la condición humana el cristiano se infiere creatura, el gnóstico divinidad" (E, 1041). La deificación del género humano que Gómez Dávila atribuye a los gnósticos es para él el principio fundante del pensamiento y la práctica de la democracia de nuestro tiempo. "La divinidad del hombre no es conclusión a que el igualitarismo llegue, es la convicción sobre la cual se funda" (E, 1047). Sin esa premisa, "aunque realmente fuéramos iguales, la igualdad no tiene por qué ser un ideal" (E, 293). Con ella, el progreso deviene "la rampa de acceso a la divinidad" (E, 1034), mito falaz — agrega el mismo escolio- que cubre "la discrepancia entre la pretensión del hombre y su miseria".

Esta visión histórica respalda el desplante estupendo con que Gómez Dávila desafía todos los cánones de la llamada "corrección política". Recojo una decena de ejemplos entre cientos.

${ }^{27}$ Cf. Michael A. Williams, Rethinking “gnosticism”: An argument for dismantling a dubious category, 1996. Por cierto, Gómez Dávila — que no tuvo oportunidad de conocer el libro de Williams - usa 'gnosticismo' sin la menor reserva. 
Un solo tipo de sociedad tuvo un contrato social por raíz histórica y por resorte ético: el feudalismo (E, 164).

El dinero sólo mana sin mancha de la espada o del trigo (E, 723).

Civilizada es la época que no reserva la inteligencia para las faenas profesionales (E, 612).

No esperemos que la civilización renazca, mientras el hombre no vuelva a sentirse humillado de consagrarse a tareas económicas (E, 461).

Sin propiedad "injusta", amparada por una legislación "clasista", nadie escapa a la necesidad de vivir en postura servil (E, 631).

La sociedad que oficialmente niegue la existencia de clases sociales se convierte subrepticiamente en predio de la clase social larvada que la gobierna (E, 293).

La sociedad del futuro: una esclavitud sin amos (E, 117).

El hombre moderno no imagina fin más alto que el servicio a los antojos anónimos de sus conciudadanos (E, 222).

La sociedad industrial está condenada al progreso forzado a perpetuidad (E, 170).

Los dos problemas cardinales del mundo actual: expansión demográfica y deterioro genético, son hoy insolubles. Los principios liberales vedan la solución del primero, los principios igualitarios la del segundo (E, 712).

Para terminar, encaro la cuestión implícita en la columna de Matías Rivas que mencioné al principio: ¿cómo entender el silencio de nuestros intelectuales en torno a un escritor de la envergadura de Gómez Dávila? Sobre muchos pesa el temor a que el igualitarismo rampante los juzgue "culpables por asociación" con un autor que tan francamente se le opone. Pero hace falta otra explicación para el silencio de quienes nos deleitamos con la political incorrectness. En mi caso, fue la ignorancia. Ahora que los conozco, no tengo dificultad en percibir y reconocer que los escolios de Gómez Dávila suelen tener fuerza y dar en clavos (aunque torciéndolos a veces). Me parece que, tal como Rivas sugiere, trasmiten más enjundia que la mayoría de los aforismos de Cioran. Pero si leo alternativamente a Gómez Dávila y a un crítico europeo de la cultura contemporánea tan ocurrente y discurrente como Sloterdijk, pronto advierto la sequedad y comparativa monotonía de las 
ideas que maneja el maestro colombiano. La exigua complejidad de la vida al pie de los Andes en el siglo XX les ha restado matices y eximido de implicaciones y complicaciones ${ }^{28}$. Y el sostenido repudio al mundo actual que las empapa habrá quizás preservado la honra de quien las pensó, pero les cierra las puertas del futuro.

\section{OBRAS CITADAS}

Cioran, Emil. Euvres. Paris: Gallimard, 2011.

Cordua, Carla. "Borges y la metafísica”. La Torre, N.S., 2: 629-638 (1988).

Diogenis Laertii vitae philosophorum. Edidit H.S. Long. Oxford: Clarendon Press, 1964, 2 vols.

Gómez Dávila, Nicolás. Escolios a un texto implícito. Madrid: Atalanta, 2009. (Abreviado: E).

Gómez Dávila, Nicolás. Escolios a un texto implícito. Selección. Selección de textos: Rosa Emilia Gómez de Restrepo. Bogotá: Villegas Editores, 2001.

Gómez Dávila, Nicolás. Sucesivos escolios a un texto implícito. Santafé de Bogotá: Instituto Caro y Cuervo, 1992.

Gómez Dávila, Nicolás. Textos I. Bogotá: Voluntad, 1959.

Gómez Dávila, Nicolás. Textos, Madrid: Atalanta, 2010.

Hopkins, Gerard Manley. "The leaden echo and the golden echo", http://www. bartleby,com/122/36html.

Kant, Immanuel. Gesammelte Schriften herausgegeben von der Preußischen Akademie der Wissenschaften, der Deutschen Akademie der Wissenschaften zu Berlin, und der Akademie der Wissenschaften zu Göttingen. Berlin: 1902- .

Pizano de Brigard, Francisco. "Semblanza de un colombiano universal: Las claves de Nicolás Gómez Dávila". Revista del Colegio Mayor de Nuestra Señora del Rosario, No 542 (1988), pp. 9-20.

Rivas, Matías. "Arribismo académico". La Tercera, viernes 30 de noviembre de 2012, p. 83.

Unamuno, Miguel de. Visiones y comentarios. Buenos Aires: Espasa-Calpe, 1949.

Williams, Michael A. Rethinking "gnosticism": An argument for dismantling a dubious category. Princeton, NJ: Princeton University Press, 1996.

28 Tengo presente que el propio Cioran escribió, a propósito de Borges: "C'est le néant sudaméricain qui rend les écrivains de tout un continent plus vivants, plus ouverts et plus divers que ne le sont les Européens de l'Ouest, paralysés par leur traditions et incapables de sortir de leur prestigieuse sclérose" (Euvres, 2011, p. 1226). Pero elegí para mi lectura comparativa a un autor europeo vivo y extraordinariamente vivaz, abierto y variado, a quien no frena tradición alguna, ni aflige la "esclerosis prestigiosa" a la que se entregó temprano su adversario Jürgen Habermas, por ejemplo. 